\title{
CHARACTERISTICS OF URBAN HEAT ISLAND IN ENUGU DURING RAINY SEASON *ENETE, I.C. ${ }^{1}$ and ALABI, M. 0 . $^{2}$ \\ http://dx.doi.org/10.4314/ejesm.v5i4.8
}

Received 2nd July 2012; accepted 10th August 2012

\begin{abstract}
The rainy season UHI characteristics at several sites in Enugu urban were evaluated using paired measurement programme. The aim was to determine the characteristic of urban heat island in the city during rainy season periods. The study was undertaken in Enugu municipality in the months of June - July of 2006 and 2007. The results indicate that UHI at day and night during rainy season were very different. A downtown-centered heat island was observed both day and night. The day time variations were strongly correlated to the amount of tree shading while in the night, city climate was highly correlated to sky-view factors and thermal properties in the city. Maximum UHI was about 32c during the day and hour-to-hour difference was observed at night around (1800hrs to 2300hrs). UHI over Enugu have been analyzed and results reveal some spatial and temporal characteristics. The UHI has been found to occur throughout the day and night during rainy season. Its structure was observed to be greatly influenced by weather, city, metabolism, anthropogenic activities and local geographic features, land-use, land-cover as well as vegetation and population.
\end{abstract}

Keywords: Measurement, Temperature, Urban, Rural, Rainy, Vegetation.

\section{Introduction}

One particularly important environmental characteristics of cities is the "Urban heat Island" where by Urban areas are hotter than their surrounding county site. This is a real problem, which will be made even worse by climate change (Roland, 2010). It has therefore become a prime focus of research. An urban heat Island is the name given to describe the characteristic warmth of both the atmosphere and surfaces in cities (Urban areas) compared to their rural surroundings. The heat Island is an example of unintentional climate modification when Urbanization changes the characteristic of the Earth's surface and atmosphere.

This urban heat Island may be up to 10$15^{\circ} \mathrm{c}$ under optimizing conditions. With increasing urban development, heat Islands may increase in frequency and magnitude. These heat Islands have impacts that range from local to global scales and highlight the importance of urbanization to environmental change.

The scientific awareness of urban climate anomaly arose at least in the mid-eighteenth century (Lansberg, 1981). However, experimental studies had not been carried out until the development of meteorological instruments such as the thermometer in the mid-nineteenth century (Oke, 1991).It was especially from the mid-twenty Century that urban heat Islands was observed practically in most parts of the world except in extreme cold climates (Emmanuel, 2005).

Heat Islands develop when a large fraction of the natural land cover in an area is replaced by built surfaces that trap incoming solar radiation during the day then re-radiate it at night (Oke, 1982; Quattrochi et al., 2000). This shows the cooling process thereby keeping nighttime air temperature high relative to temperatures in less urbanized areas (Oke, 1982). Heat Islands of varying extent and magnitude have been observed in most urbanized areas in the world (Lansberg, 1981). As before, it is evident that urban heat island would cause various serious environmental problems in the tropics, but the urban climate of tropical cities has not been intensively studied (Oke, 1982). This story is not different for Enugu Urban. This study, therefore investigates the spatial characteristics of urban heat Island in the city of Enugu during rainy season.

\footnotetext{
${ }^{I}$ Department of Geography and Meterology,

Nnamdi Azikiwe Uinversity, Awka, Nigeria

${ }^{2}$ Department of Geography and Planning

Kogi state university, P.M.B. 1008, Anyigba, Kogi State,

*Corresponding Author email ugwuenete@yahoo.co.uk
} 


\section{Conceptual framework}

Modification of the earth's surface through urbanization can have a dramatic impact on local climates; and one of them is a phenomenon known as the urban Heat Island (UHI). Cities are typically about $4^{0} \mathrm{C}$ hotter than the surrounding countryside and the larger they are, the bigger the difference. In a city, although heating, air-conditioning and transport, all produce energy, this is surprisingly small component of their heat balance - only about 50W m² (Roland, 2010).

The amount of energy stored is a function of the mass and heat capacity of the layer and the rate at which energy is lost and absorbed. The ambient temperature within will be a function of the amount of energy stored there, the nature of the surface, its albedo, water heat capacity and thermal conductivity. The ambient temperature is an element of the microclimate modified by such surface properties (Oke, 1987). In rural areas, vegetation reflects about a quarter of the incoming short-wave radiation (visible light or short- wavelengths). Of the three-quarters that are absorbed, much of the energy is used to evaporate water from leaves a process known as "evapotranspiration". This cools the vegetation, which therefore radiates little longwave radiation (infrared) and even less energy remains to heat the air by convection and to heat the soil by conduction.

In cities, where vegetation has largely been replaced by buildings and roads, the energy balance is dramatically altered. Dark, artificial materials reflect less and absorb more radiation than vegetation. This lower "albedo" means that only about $10 \%$ of the suns radiation is reflected down into urban 'canyons' (Oke, 1982). Almost all of this energy goes into heating the dry roads and roofs, where it is either stored in bricks and mortar or heats the air above, thus raising daytime surface and air temperature well above those of the surrendering countryside. However, this "average" effect is complicated by the presence of parks, forested areas, rivers and streams and other non-urban features that exist in the landscape. This, detailed spatial investigation of the UHI can reveal micro- climatic details that explain how various surface features enhance UHI effect.

At night the difference in temperature between the countryside and the urban can become even more pronounced. Cities cool down more slowly because there is more heat stored in its buildings, which continues to dissipate into the night; (Quattrochi et al., 2000); there is more pollution to trap longwave radiation; and within urban canyons less of the cool sky is visible, so less radiation can escape.

All this causes major problems for citydwellers. The rise in urban air temperature above that of the surrounding countryside, which can reach $7^{\circ} \mathrm{C}$ in metropolis, makes cities less comfortable and less sustainable places to live in during rainy season months. Soaring temperature increase ill health and can even kill people during heat waves.

In an urbanized environment, natural cycle of heating and cooling are significantly modified by: man-made structures (buildings, paved surfaces); anthropogenic heat sources: industrial processes, internal combustion engines. The heat from these sources cumulates to give rise to pockets of high temperatures in urban centers that we call urban heat Island (UHI). Thus areas with high infrastructural development, industrial concentration and high density buildings and Lange population are expected to always encourage urban heat Island (UHI).

Urban heat islands are of interest primarily because they affect so many people. Urban heat islands directly influence the health and welfare of urban residents. In United States alone, an average of 1000 people die each year of extreme heat. This is higher than due to all other weather events combined (Changnon $e t$ $a l .$, 1996). Research has shown that mortality rate during a heat wave increases exponentially with maximum temperature (Buechley et al., 1972), an effect that is exacerbated by urban heat island. The nighttime effect of urban heat island can be particularly harmful during a heat wave, as it deprives urban residents of the cool relief found in rural areas during the night (Clarke, 1972). Another consequence of urban heat island is the increased energy required for air 
conditioning and refrigeration in cities that are in hot climates (Adinna et al., 2009).Since urban heat island may affect inhabitants of Enugu in different forms, it becomes necessary to study the pattern and form it may take in Enugu urban; hence, the need for this study.

\section{Study Area}

Enugu State is one of the states in southeastern Nigeria. Its capital is Enugu. The state was created in 1991 from the old Anambra State. Enugu state is located within latitude $6^{0} .00{ }^{\prime} \mathrm{N}$ and $7^{0} .00^{\prime} \mathrm{N}$ and longitude $7^{0} .00^{\prime} \mathrm{E}$ and $7^{0} .45^{\prime} \mathrm{E}$. The state is called the Coal City State because of the discovery of coal in a commercial quantity in Enugu Urban in 1909. Enugu was then the capital of East Central State of Nigeria. Some of the important towns in the State are Enugu Urban, Oji, Udi and Nsukka Urban (Nnamani, 2002).

Enugu Urban which is the study area is made up of Enugu East, Enugu North, and Enugu South (figure 1.). Enugu Urban is also located within latitude $6.24^{\circ} \mathrm{N}$ and $6.30^{\circ} \mathrm{N}$ and longitude $7.27^{\circ} \mathrm{E}$ and $7.32^{\circ} \mathrm{E}$. It is an hour's drive from Onitsha, one of the biggest commercial cities in Africa and 2 hours drive from Aba, another very large commercial city, both of which are trading centers in Nigeria. Enugu Urban shares boundary with Igbo Etiti and Isi-Uzo Local Governments in the north, Udi local Governments in the west, Nkanu West Local Government in the south and part of Nkanu East Local Government Area in the east. There are 18 prominent residential areas in the Urban. These are Abakpa, Trans-Ekulu, Nike, GRA, Ogui, Asata, New Heaven, Obiagu, Ogbete, Iva valley, Independence Layout, Achara Layout, Ugwuaji, Maryland, Awkanaw, Uwani, Agbani, and Coal Camp.
Enugu Urban is the most developed urban area in Enugu state.

The study area falls within the humid tropical rain forest belt of Southeastern Nigeria. It has two seasons, the raining season and the dry season. The rainy season which is characterized by heavy thunderstorms lasts from April to October with the South Westerly moisture accompanied by air mass moving northwards into the city. The turbulent runoff result in leaching, sheet erosion and eventually gullies (Akabuike, 1990). The mean temperature varies from about $20.30^{\circ} \mathrm{C}$ to about $32.16^{\circ} \mathrm{C}$ in the dry season and rainy season respectively, (Akabuike, 1990). During the dry season the humidity is lower than in the rainy season. Temperature is most often high during the day and low during the night. This results in high evaporation rate during the day. Harmatten which occurs between the months of November and February is always accompanied by poor visibility mostly at night and early in the morning. The rivers and streams which flow from the Udi hills dissect the study area into several sections. Thus there are rivers such as Ekulu, Idaw, Asata and Nyaba Rivers which separates Enugu South from Nkanu East. These rivers have many tributaries; the study area is generally marked by low land, slopping towards Enugu South Local Government Area and the Southern part of Enugu East Local Government Area. The elevations are between 182.88 meters and 219.45 meters above the sea level. Below is a table showing the population of each local government area that make up the study area. This is based on the figure of National population Census of 2006. 


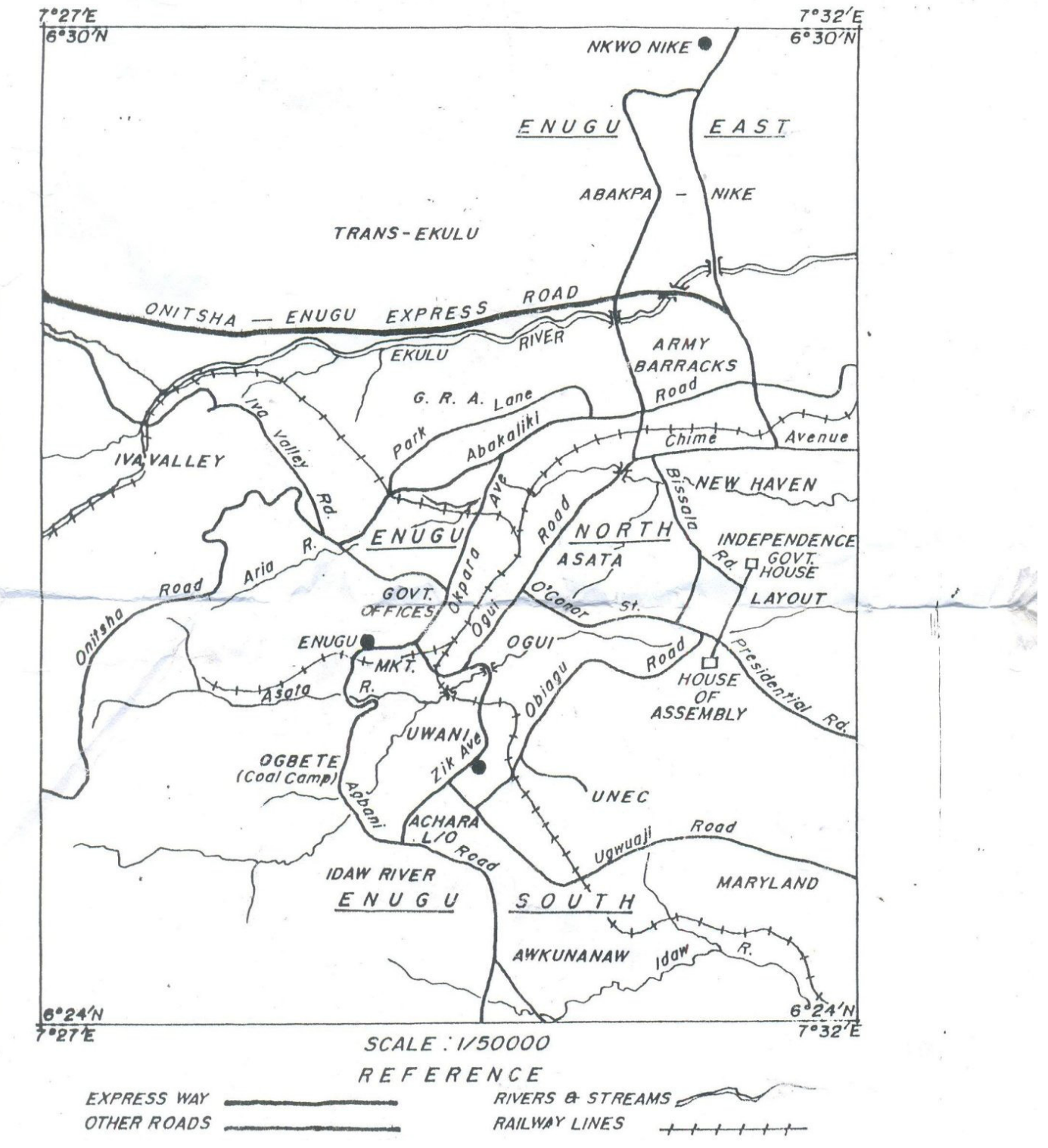

Figure 1 Map of Enugu Urban

Source: Ministry of Lands and Survey, Enugu

\section{Methodology}

Data collection spanned over two seasons (2006 to 2007). The essence was to capture the peak periods, frequency, magnitude and seasonality of urban heat variations in places. The months to June-July were selected because of high rainfall during this period. Temperature data were collected during the day and night. Quadrant sampling method and purposive sampling were employed based on location, presence of vegetation and other variables. The following land use/land cover sites were selected for data collection. a. High-density, high-rise, non-residential areas with no greenery (DTL).

b. High density, high-rise, residential areas with low greenery (HDR).

c. Medium density, mixed residential (some residential, some commercial/ institutional area with a greenery extent between DTL and HDR.

d. Areas with similar land-use, building density and greenery one having more fully developed vegetation canopy than the other (LVR and LOR) 
During the study period, transect and fixed point measurements were taken hourly and averaged over a month. All temperature differences were calculated as site temperatures minus reference temperature. Thus a negative (-) temperature deference indicates that the site was cooler than the reference station; and positive (+) indicated the site was Warmer than the reference station. The reference station is the rural environment.

\section{Results}

\section{Rainy Season (Day-Time)}

Table 1 shows temperature variations during stable atmospheric conditions during the day.

Table 1 Temperature Variation under stable Day-Time Conditions

\begin{tabular}{|l|l|l|}
\hline Sites & Location Names & $\begin{array}{l}\text { Temperature } \\
\text { Difference }\end{array}$ \\
\hline DTL & Ogui Road & +0.64 \\
\hline LOR & $\begin{array}{l}\text { Independence } \\
\text { L/O }\end{array}$ & -0.22 \\
\hline LVR & GRA & -3.3 \\
\hline NW2 & UNEC & -2.0 \\
\hline HDR & Achara L/O & -2.1 \\
\hline
\end{tabular}

The downtown location site was the warmest $(+0.64)$ warmer than the residential sites. Places like Ogui road, Asata, Ogbete, Okpara Avenue and parts of zik Avenue were warmer than neighboring sites. The high density, urban residential sites (HDR)- Achara Layout, and heavily vegetated urban sites (LVR)-(GRA, with fully developed vegetation canopy were the coolest $(-2.31$ and -3.3$)$ respectively. The low-density residential sites (LOR) like independence layout, was only $0.22^{\circ} \mathrm{C}$ cooler than the reference site. Except for sites (NW2) where institutions and residential quarters are housed, hour-to-hour variation in air temperature during the daytime was not much. The NW2 sites witnessed higher temperatures during the day than in the night.

The number of sites that witnessed unstable conditions on multiple days was very few (sites DTL, LVR and NW2); the patterns were very similar to those produced by stable conditions. The average air temperature differences during unstable day-time are shown in table 2 .

Table 2 Temperature under unstable DayTime Conditions

\begin{tabular}{|l|l|l|}
\hline Sites & $\begin{array}{l}\text { Location } \\
\text { Names }\end{array}$ & $\begin{array}{l}\text { Temperature } \\
\text { Difference }\end{array}$ \\
\hline DTL & Ogui Road & +1.52 \\
\hline LVR & GRA & -3.45 \\
\hline NW2 & UNEC & -3.0 \\
\hline
\end{tabular}

Under unstable, conditions too, downtown location sites (DTL) were the warmest. Maximum day time UHI was about $3.2^{\circ} \mathrm{C}$ and hour-to-hour difference was about $3.5^{\circ} \mathrm{C}$. Unlike stable conditions, differences between LVR and NW2 under unstable conditions were $0.45^{\circ} \mathrm{C}$ warmer than the reference site. Rainy Season ( Nighttime)

Unlike the daytime temperature differences, night temperature variation (DTN) showed a clear downtown centered heat Island. Table 3 clearly depicts this variation.

Table 3 Rainy Season Temperature during the Night

\begin{tabular}{|l|l|l|}
\hline Sites & Location Names & $\begin{array}{l}\text { Temperature } \\
\text { Difference }\end{array}$ \\
\hline DTL & Ogui Road & +1.48 \\
\hline LOR & $\begin{array}{l}\text { Independence } \\
\text { L/O }\end{array}$ & -0.64 \\
\hline LVR & GRA & -0.34 \\
\hline NW2 & UNEC & -0.39 \\
\hline HDR & Achara L/O & -0.52 \\
\hline
\end{tabular}

All residential sites were cooler than the reference site (from- $0.34^{\circ} \mathrm{C}$ to $0.34^{\circ} \mathrm{C}$ ) while the downtown location was up to $1.48^{\circ \mathrm{C}}$ warmer. The intra-urban differences among the other sites (LOR, LVR, NW2 and HDR) however, were very small.

\section{Discussion}

Rainy season heat Island at the city wide scale correlated well with ground cover characteristics. Green cover alone explained about $40 \%$ of micro-climate variations. The influences of buildings and vegetative maturity were apparent. The magnitude of the temperature differences decreased as background climate became hotter. But hotter conditions led to higher intra-urban thermal 
comfort difference than the cooler nights. This finding highlights the need to distinguish between temperature Islands and thermal comfort Islands. The former peaks at clear calm nights while the latter reaches its maximum under overcast or hazy conditions.

Under very hot conditions, the low ground cover at the more open residential sites did not significantly improve day-time cooling. This suggests that shading was more central to daytime cooling than ground cover. Extensive tree canopy produced some cooling during the day, but the cooling provided by building shade at the high-density sites (like Achara Layout) had the same effect.

The highest nighttime intra-urban air temperature difference was observed early night period (1800 hrs. to 2300hrs). Unlike day-time, the hour-to-hour variation in air temperature during the night was very significant, particularly at the residential sites. Observations showed that there was a clear downtown-centre heat Island at night. A maximum nighttime air temperature of about $2.0^{\circ} \mathrm{C}$ heat Island was observed during the study period.

\section{Conclusion}

Air temperature measurements over Enugu have been analyzed and results reveal some spatial and temporal characteristics of the UHI in Enugu. The urban heat Island has been found to occur throughout the day and night with the highest intensity occurring around $1800 \mathrm{hrs}$ and $23000 \mathrm{hrs}$, with mean values reaching $3.2{ }^{\circ} \mathrm{C}$ and $3.5^{\circ}$ during the day and night respectively. Its structure was also observed to be greatly influenced by weather, city metabolism, anthropogenic activities, local geographic features, land-use and land-cover as well as vegetation, and population.

Finally, further study is needed to examine the possible mitigation measures for the effects of urban heat Island in Enugu, focusing especially on the temperature reduction effects caused by the green areas.

\section{References}

Adinna, E.N., Enete, I.C. and Okolie, T. (2009). Assessment of Urban Heat Island and
Possible Adaptations in Enugu Urban using Landsat/ ETM. Journal of Geography and Regional Planning,2(2):30-36.

Akabuike, B.O. (1990). A Short Text on Geography Pegant Ventures, Enugu

Buechley, R.W., Van Bruggen, J. and Trippi, L.E. (1972). Heat Island=Death Island? Environmental Research, 5, 85-92.

Changnon, S.A, Kunkel, K.E. and Reinke, B.C. (1996).' Impacts and Responses to the 1995 Heat wave: A call to Action" Bulletin of American Meteorological Society, 73,14971506.

Changnon, S.A. (1992). Inadvertent Weather Modification in Urban Areas: Lessons for Global Climate Change. Bulletin of American Meteorological Society, 73, 619-627.

Clarke, J.F. (1972). "Some Effects of the Urban Structures on Heat Mortality" Environmental Research, 5, 93-104.

Emmanuel, M.R. (2005). An urban Approach to climate Sensitive Design, Spon Press.

Landsberg, H.E (1981). The Urban Climate. National Academy Press, New York,p.275.

Nnamani, C. (2002). 'By the Hills and Valleys of Udi and Nsukka' The people, Their Heritage, Their Future' Tell Magazine,No. 50, December 16, pp.64-69.

Oke, T.R (1991). Climate of city. In Baer, F (eds). Climate in human perspective, A tribute to Helmut, E Landsberg, Dordrecht, Netherlands, Kluwer Academic Publishers, pp.61-75.

Oke, T. R(1982). The Energetic basis of urban heat Island, Quarterly Journal of the Royal Meteorological Society, 108 (45), 1-24.

Oke, T.R (1987). Boundary layer climates $\left(2^{\text {nd }}\right.$ edition), London: Methuen and Co, p. 435.

Quattrochi, D., Luvall, J., Rickman, D. Estes, M. Laymon, C. and Howell, B. (2000). A decision support information for urban landscape management using thermal infrared data. Photogrammetric Engineering and Remote Sensing. 66(10), 1195-1207.

Roland, E. (2010). Urban Cool. Physicsworld.com.

(http.//physicsworld.com/cws/article/print/201 0/aug/02/urba). Retrieved 2nd June, 2012. 